\title{
Es necesario que en la práctica médica aceptemos la incertidumbre y nuestra ignorancia
} Embracing uncertainty and ignorance in medical practice

En las últimas décadas, la práctica médica se modificó a un ritmo cada vez más acelerado.

Podemos decir, con cierta aproximación, que hasta la segunda guerra mundial los médicos ejercían una medicina con muy bajos recursos y escasos conocimientos. Paradójicamente, los años transcurridos desde la mitad del siglo 19 hasta entonces, fueron denominados "la era dorada de la profesión médica". Esto se debió a un cambio en la actitud del médico, que comenzó a valorizar más la consulta con empatía, sin prisa y cauteloso con las escasas terapéuticas. Poco se podía hacer sobre la evolución natural de la enfermedad, excepto acompañar al paciente y a su familia, el don más esencial de nuestra profesión. Así, fueron ganando respetabilidad y progresivamente obtuvieron la confianza de la gente, alcanzando un gran reconocimiento en la sociedad. Debo señalar que hasta la penicilina (principios de los años 40) no hubo evidencias sólidas que algún medicamento produjese la curación de la enfermedad. En 1950, un prestigioso farmacólogo dijo: "hay una docena de medicamentos eficaces, lo demás es producto del miedo de los enfermos y de los intereses de la industria farmacéutica".

En tiempos recientes fuimos observando la inclinación del péndulo de la medicina hacia los aspectos científicos y tecnológicos, dejando cada vez más de lado el humanismo, la segunda columna de nuestra profesión. Eso produjo, la progresiva pérdida del altruismo, la empatía, la humildad y asimismo, la no aceptación de la incertidumbre que fue llevando a la falsa y nefasta creencia que los conocimientos científicos eran suficientes para ejercer bien la medicina. Esto lleva a una frecuente y perjudicial consecuencia al suponer el médico erróneamente que el proceso de curación depende solo del conocimiento biológico y de la tecnología. Sin embargo, muchas veces el que más sabe de ciencia, no es el mejor médico, y mientras la ciencia crece constantemente parecería que los buenos médicos son cada vez más raros. (Jasper)

Los modelos tradicionales de educación médica refuerzan el concepto de infalibilidad; se supone que no podemos cometer errores y no somos preparados, ni en la Universidad ni en los años de formación, para cultivar una actitud crítica que nos permita enfrentar el error.

El "aura" de infalibilidad en la práctica médica es sin duda falsa, debido a que al igual que todos los seres humanos, indefectiblemente nos vamos a equivocar más allá de nuestras capacidades.

Estos aspectos contribuyeron, y aun lo hacen, a que muchos médicos no puedan tolerar la incertidumbre y no sean concientes de que nuestra ignorancia es mucha.

Stuart Firestein, profesor de Neurociencias y Jefe del Departamento de Biología de la Universidad de Columbia, abordó el tema de la ignorancia muy originalmente. Dictaba un curso de varios meses denominado "Neurociencia celular y molecular", que era formal y exigente. En una oportunidad, al final del curso, comenzó a ver que varios de los estudiantes creían que ya sabían "todo" acerca de las neurociencias y asimismo, suponían que el conocimiento científico aumentaba por acumulación de nuevos hechos, concepto equivocado ya que el saber principalmente crece mediante la identificación del error y el crecimiento de la ignorancia, ambos llevan a eliminar el antiguo conocimiento.

Luego de ese parecer, Firestein decidió crear un curso sobre ignorancia y comenzó a invitar a científicos para que en especial dieran charlas de lo que no saben, es decir que se refirieran a la importancia de la ignorancia en la ciencia. ${ }^{1}$ Esa tan fascinante experiencia la volcó en un libro de publicación reciente. ${ }^{2}$

Este ejemplo nos ayuda a dilucidar cuáles son los motivos que en la práctica médica nos llevan a no cultivar la actitud crítica y la humildad elementos esenciales para aceptar la incertidumbre y reconocer todo lo que no sabemos. Para tratar de llegar al conocimiento y evitar en lo posible los errores, es imprescindible tolerar la incertidumbre, ya que ante situaciones complejas nos permitirá reflexionar acerca de cuáles serían las opciones más adecuadas antes de tomar decisiones.

Algunas frases son reflejo de varias reflexiones críticas sobre el saber. Un antiguo proverbio italiano dice así: "Chi sa che non sa, sa. Chi sa che sa,non sa" ("Quien sabe que no sabe, sabe. Quien sabe que sabe, no sabe"). Asimismo, 
varios médicos dejaron ejemplos propios de su propia experiencia en la práctica profesional, cito solo a dos.

Bill Rogers, afamado clínico estadounidense, nos dejó una sabia reflexión: "No es todo lo mucho que no conozco lo que me preocupa, son las cosas que creo que conozco las que me traen problemas" y el Dr. Murray Enkin, Profesor Emérito de Obstetricia les decía a los alumnos de medicina en la clase inicial de su cátedra: "La mitad de las cosas que les voy a decir son muy probablemente erróneas. El problema es que no se cuál mitad es". 3

Tradicionalmente, la medicina se aprendía al lado del enfermo con el ejemplo de los maestros, eso fue y sigue siendo muy bueno y necesario, aunque es de notar que hay menos maestros. Los cambios tecnológicos llevaron progresivamente a acceder a copiosa información, aunque no se tiene en cuenta que la mayoría es irrelevante e innecesaria para ser un buen médico.

Un riesgo es que aquellos médicos en formación que sólo tengan abundante información supongan que también saben mucho, cuando es justo lo contrario.

Es necesario comprender que solo el espíritu crítico nos permitirá ser muy escépticos con los nuevos conceptos que parecen de una verdad irrefutable. Así, podremos tomar adecuadas decisiones y a saber lo que se debe hacer, pero muy en especial a lo que no debemos hacer, "en medicina, no todo lo que se puede hacer, se debe hacer"

Asimismo, debemos transmitir a los más jóvenes que en la ciencia el deslumbramiento por lo nuevo tiene "patas cortas"; lo que hoy es cierto, mañana ya no lo es.

Deseo brevemente referirme al pensamiento del médico cuando debe tomar decisiones y realizar un adecuado juicio clínico. En esos momentos cruciales, muchas veces el pensamiento toma caminos inapropiados que llevan a no reconocer que el deslumbrante avance tecnológico y científico se desarrolla en situaciones de incertidumbre; y entonces, la información engaña al pensamiento y confunde el juicio clínico. ${ }^{4}$ Asimismo, en el desvío del pensamiento influye la muy extendida creencia de que la medicina es solo una ciencia, lo cual sin ninguna duda no representa la realidad y no hace justicia a lo que realmente es ni a lo que idealmente debería ser. La Dra. Katryn Montgomery nos deja una excelente reflexión sobre este aspecto: "La compleja empresa social que la medicina encarna está muy alejada de las visiones ingenuas de la ciencia biológica que aún erróneamente sobreviven en las mentes de muchos de sus defensores aunque no es un reflejo fiel de lo que es la medicina, siendo que está gobernada por la contingencia". 4

Finalmente, deseo enfatizar algo que respalda nuestro compromiso para mejorar la práctica médica. Es necesario comprender que la educación médica es tanto intelectual como moral y por lo tanto debemos preparar al estudiante de medicina y al médico para que sepan convivir con la incertidumbre y nuestra ignorancia.

\section{Dr. José M. Ceriani Cernadas} Editor

http:/ /dx.doi.org/10.5546/aap.2016.98

1. La nueva ilustración evolucionista:la ignorancia y la ciencia. [Consulta 29 de diciembre de 2015]. Disponible en: http:/ / ilevolucionista.blogspot.com.es/2014/01/la-ignorancia-yla-ciencia.html

2. Firestein S. Ignorance: How it drives Science. Oxford: Oxford University Press, 2012.

3. Enkin MW. The seven stages of the ignorance. Birth 2008; 35(3):169-70.

4. Montgomery K. How doctors think: clinical judgment and the practice of medicine. Oxford: Oxford University Press, 2006. 